\section{Cartoon Editorial}

Check for updates

\title{
Necessary or Sufficient Condition for Gastroscopy
}

\section{Min Suk Chung $(1)$}

Department of Anatomy, Ajou University School of Medicine, Suwon, Korea

- See the article "Common Locations of Gastric Cancer: Review of Research from the Endoscopic Submucosal Dissection Era" in volume 34, number 35, e231.

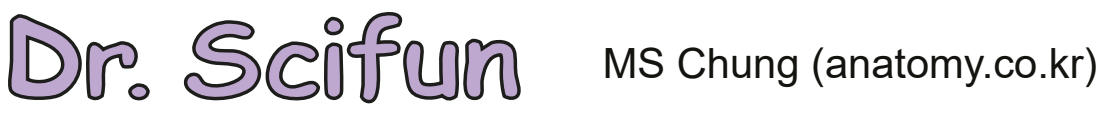

Necessary or sufficient condition for gastroscopy

Department of Anatomy, Ajou University

School of Medicine, 164 World Cup-ro,

Yeongtong-gu, Suwon 16499,

Republic of Korea.

E-mail: dissect@ajou.ac.kr

(c) 2019 The Korean Academy of Medical

Sciences.

This is an Open Access article distributed under the terms of the Creative Commons Attribution Non-Commercial License (https:// creativecommons.org/licenses/by-nc/4.0/) which permits unrestricted non-commercial use, distribution, and reproduction in any medium, provided the original work is properly cited.

ORCID iDs

Min Suk Chung (iD

https://orcid.org/0000-0002-0527-9763

\section{Disclosure}

The author has no potential conflicts of interest to disclose.
For police to patrol the suspected area is a necessary condition.

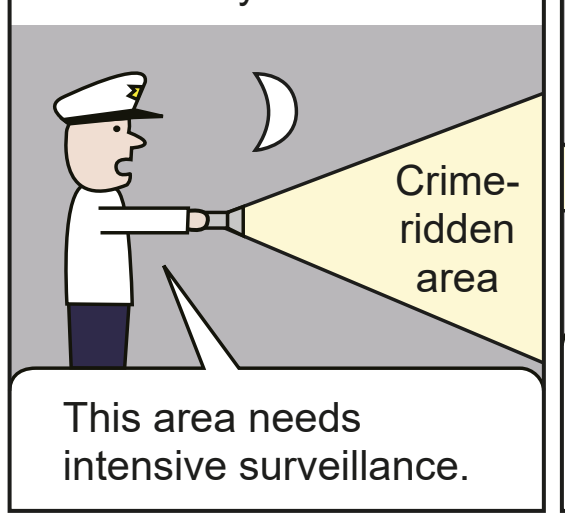

For endoscopist to check the suspected area is a necessary condition.

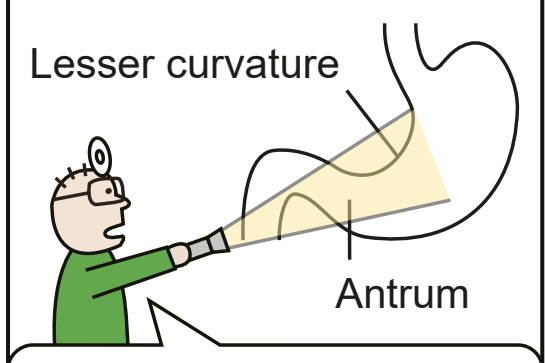

This area needs intensive surveillance.
To patrol all the spots is a sufficient condition.

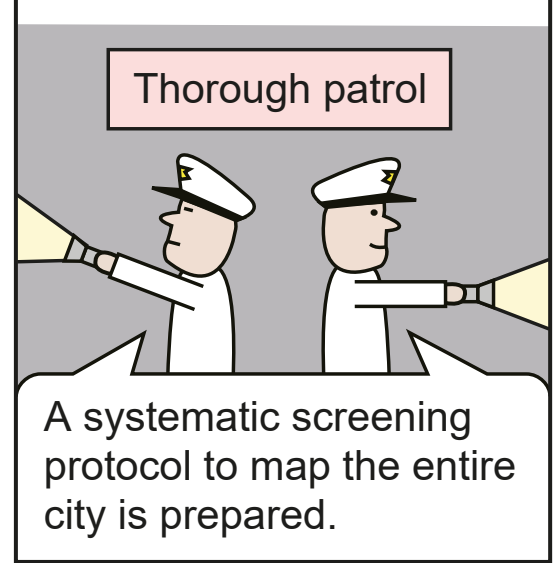

To check all 24 spots of stomach is a sufficient condition.

\section{Thorough gastroscopy}

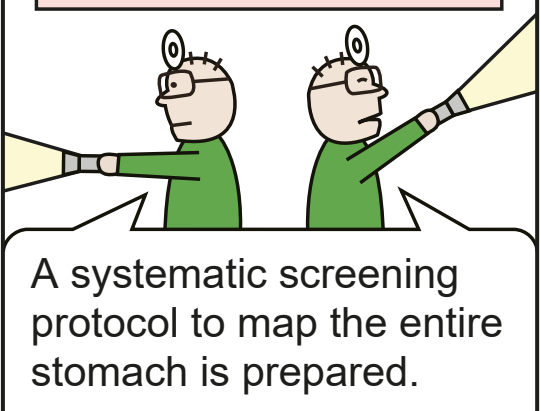

